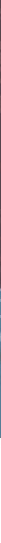

\title{
How have teachers' salaries evolved and how do they compare to those of tertiary-educated workers?
}

- Between 2005 and 2014, teachers' statutory salaries decreased in real terms in one-third of the countries and economies with available data.

- Teachers' salaries usually increase with the level of education they teach. The salary gap between upper secondary and other teachers has narrowed between 2005 and 2014.

- In 2014, on average across OECD countries, teachers' actual salaries at pre-primary, primary and secondary levels are $11 \%$ to $25 \%$ lower than those of tertiary-educated workers.

Concepts and definitions

Salary refers to the gross, pre-tax salary from the employee's point of view (including any social security or pension scheme contributions paid by them, even if these contributions are deducted automatically from their gross salary by the employer). It excludes any social security and pension contributions paid by their employers.

Statutory salary after 15 years of experience with typical qualifications refers to the scheduled annual salary of a full-time classroom teacher holding the most frequent qualification (i.e. the one held by most teachers working at a given level of education). It includes only those allowances and bonuses payable to all teachers.

Actual salaries for teachers (aged 25-64) refer to the annual average earnings received by full-time teachers aged 25 to 64 , before taxes. Actual salaries include work-related payments, such as annual bonuses, extra pay for holidays and sick-leave pay. They do not include income from other sources, such as government social transfers, investment income and any other income that is not directly related to their profession.

Earnings for workers with tertiary education are the average earnings for full-time, full-year workers aged 25-64 with an education at tertiary level based on the 2011 International Standard Classification of Education (ISCED 2011).

All values expressed in equivalent USD are converted from national currency using purchasing power parities for private consumption, and the deflator for private consumption is used to convert salaries to constant prices.

Compensation and working conditions are important factors for attracting, developing and retaining a highly qualified and skilled labour force. Teachers' salaries in particular can have a direct impact on individual decisions to enrol into teacher training, to become a teacher upon graduation or to return to the teaching profession. Salaries can also play an important role in the retention of teachers as the higher the salaries, the less likely people may be to choose to leave the profession (OECD, 2005).

Teachers' salaries represent the largest cost to education systems: in 2013 compensation of teachers accounted for close to two-thirds of current expenditure by educational institutions at the primary and secondary levels on average across OECD countries. Constraints on public budgets resulting from the economic downturn and austerity policies following the financial crisis of 2008 have required policy makers to address two conflicting priorities: reducing government expenditure (particularly in relation to public payrolls) and maintaining the attractiveness of the teaching profession. Between 2008 and 2013, public expenditure on education increased in real terms by $5 \%$ on average across OECD countries, compared to an average increase of $7 \%$ in public expenditure for all services.

\section{Teachers'salaries decreased in real terms following the economic downturn in some countries}

In 2014 across OECD countries the statutory salaries of teachers with 15 years of experience and typical qualifications averaged USD 39245 at the pre-primary level, USD 42675 at the primary level, and USD 44407 and USD 46379 at the lower and upper secondary levels (general programmes). However, salaries vary considerably from country to country. For example, at the lower secondary level, annual salaries ranged from less than USD 20000 in the Czech Republic, Hungary and the Slovak Republic to more than USD 60000 in Canada, Germany, the Netherlands and the United States, and exceeded USD 110000 in Luxembourg. Between 2005 and 2014 statutory salaries have increased in real terms by $6 \%$ at the pre-primary level, 4\% at the primary level, $3 \%$ at the lower secondary level and $1 \%$ at the upper secondary level, on average across OECD countries. These overall increases mask different trends among countries, however. At the lower secondary level of education teachers' salaries decreased significantly between 2005 and 2014 in England (United Kingdom), Greece, Italy, Portugal, Scotland (United Kingdom) and Spain (Figure 1). At the pre-primary, primary and secondary levels these decreases reached more than $10 \%$ in England (United Kingdom) and Portugal, and up to $30 \%$ in Greece.

With the financial and economic crisis that hit the world economy in 2008, changes in statutory salaries among the 29 countries with available data show different patterns during the periods 2010-12 and 2012-14 (Figure 1). In most countries, salaries either 
increased over both periods or decreased over both periods. Salaries decreased continuously in nearly one-third of the countries and economies, all of them in Europe, while they increased continuously in more than one-third (mostly countries outside Europe).

For example over the period 2010-12, salaries in Portugal decreased as a result of two successive decreases (in 2011, monthly salaries over EUR 1500 were reduced as part of a reform package, and in 2012 salaries for civil servants - including teachers covered 12 months instead of 14 months, as had previously been the case). In England (United Kingdom), teachers' salaries were frozen between 2011 and 2012 at all levels of education, followed by a below-inflation increase of 1\% in the following years for the public sector as a whole, all due to the financial crisis. In Hungary, the Slovak Republic and Turkey, decreases in salaries between 2010 and 2012 were counterbalanced by a larger increase in salaries between 2012 and 2014

Changes in the level of salaries of teachers have not been mirrored by changes in teaching hours (it should be noted that trend data on total working time for teachers are not available). Total teaching time remained stable over the period 2005-14 in most countries. However, both teaching time and statutory salaries increased by $10 \%$ or more in Israel (primary and lower secondary) and Luxembourg (secondary). In a few countries, salaries and teaching hours moved in the opposite direction. These changes are particularly marked in Japan at primary and secondary levels where teaching time increased by $20 \%$ or more while salaries decreased by nearly 7\% between 2005 and 2014. In contrast, in Turkey, at upper secondary level, teaching time decreased by $12 \%$ while salaries increased by $18 \%$ during this period.

Figure 1. Change in lower secondary teachers' statutory salaries (2005, 2010, 2012 and 2014) Index of change between 2005 and 2014 ( $2012=100$, constant prices) for statutory salaries of teachers with 15 years of experience and typical qualifications

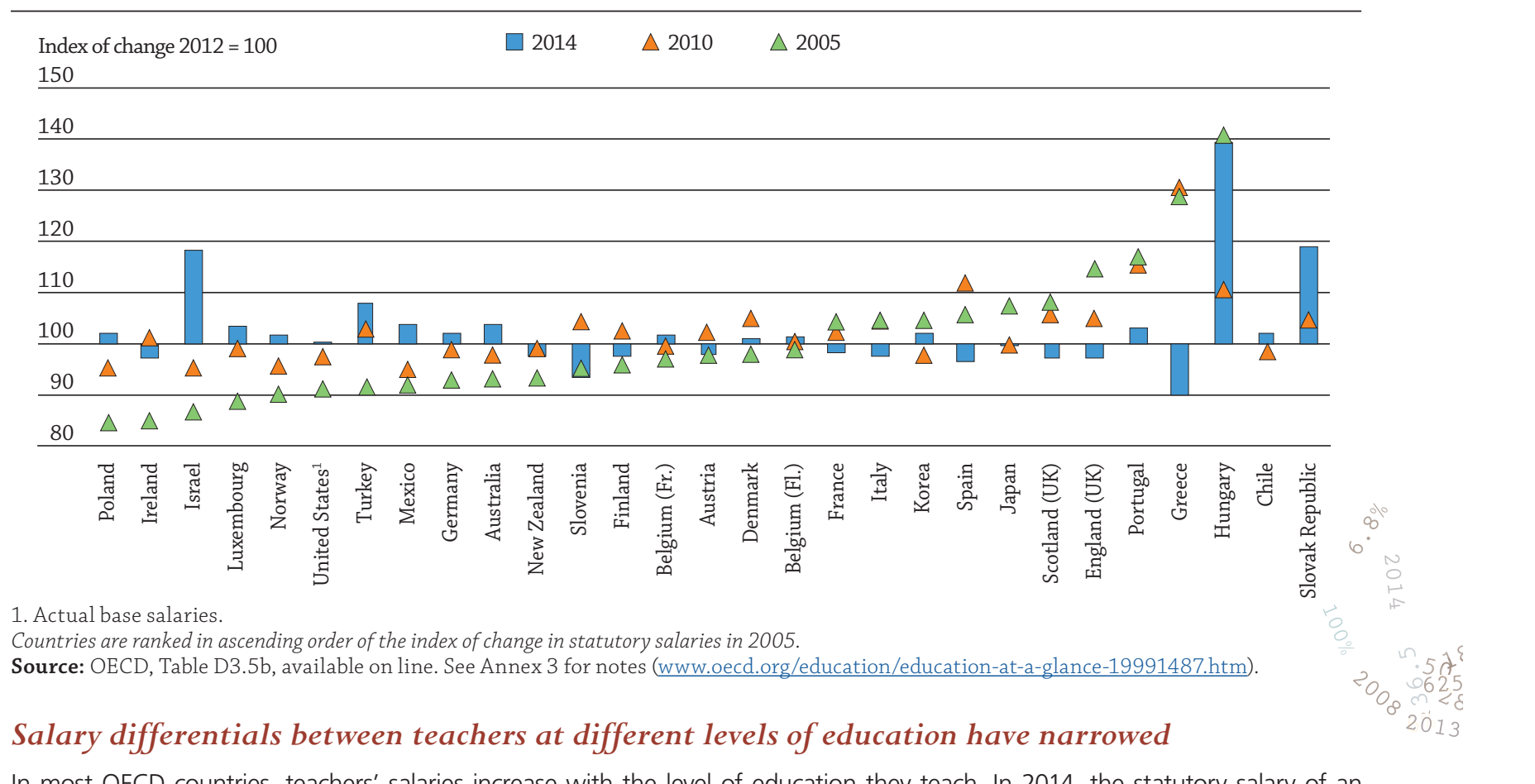

In most OECD countries, teachers' salaries increase with the level of education they teach. In 2014, the statutory salary of an upper secondary teacher with 15 years of experience and typical qualifications in Belgium, Denmark, Finland, Mexico and the Slovak Republic was at least $25 \%$ higher than that of a pre-primary teacher with the same experience and typical qualifications. In contrast, the difference was less than 5\% in Australia, Korea, Luxembourg, Slovenia and Turkey, and teachers are paid the same salary irrespective of the level of education taught in Colombia, England (United Kingdom), Greece, Poland, Portugal and Scotland (United Kingdom). This may reflect differences in qualification requirements for entry into the profession between levels, teaching and/or working hours, systems of compensation and other conditions of employment of teachers.

Between 2005 and 2014, the gap between teachers' salaries at the upper secondary level and the pre-primary level has narrowed. Across the 20 countries and economies with available data for both 2005 and 2014 - including England (United Kingdom), Greece, Poland, Portugal and Scotland (United Kingdom), where salaries are similar at these two levels of education - salaries for upper secondary teachers were less than 10\% higher than pre-primary salaries in 2014, whereas it was 15\% higher in 2005 (Figure 2). The gap decreased in most countries except Denmark and Israel. Among countries with available data, the salary gap also narrowed between teachers at upper secondary level and those at primary and lower secondary levels (for teachers with 15 years of experience and typical qualifications), but to a lesser extent: from $13 \%$ to $9 \%$ comparing upper secondary and primary salaries, and from $8 \%$ to $5 \%$ comparing upper secondary to lower secondary. 
This trend may result from differences in the way salaries of teachers are evolving at different levels of education. For example, in Luxembourg the gap between upper secondary and pre-primary teachers' salaries narrowed significantly between 2005 and 2014 due to reforms aimed at increasing pre-primary teachers' salaries. In Israel, the salaries of pre-primary teachers are significantly higher than those of upper secondary school teachers, and the gap widened as pre-primary teachers' salaries increased further. This is largely the result of the gradual implementation of the "New Horizon" reform, begun in 2008. However, Israel launched another reform in 2012 which aims to raise salaries for upper secondary teachers, which may reduce this gap. Besides Israel, only Australia had higher salaries for pre-primary teachers than for those at the upper secondary level in 2014.

Figure 2. Ratio of statutory salaries of upper secondary level teachers relative to pre-primary level teachers (2014)

Teachers with 15 years' experience and typical qualifications (pre-primary level = 100)

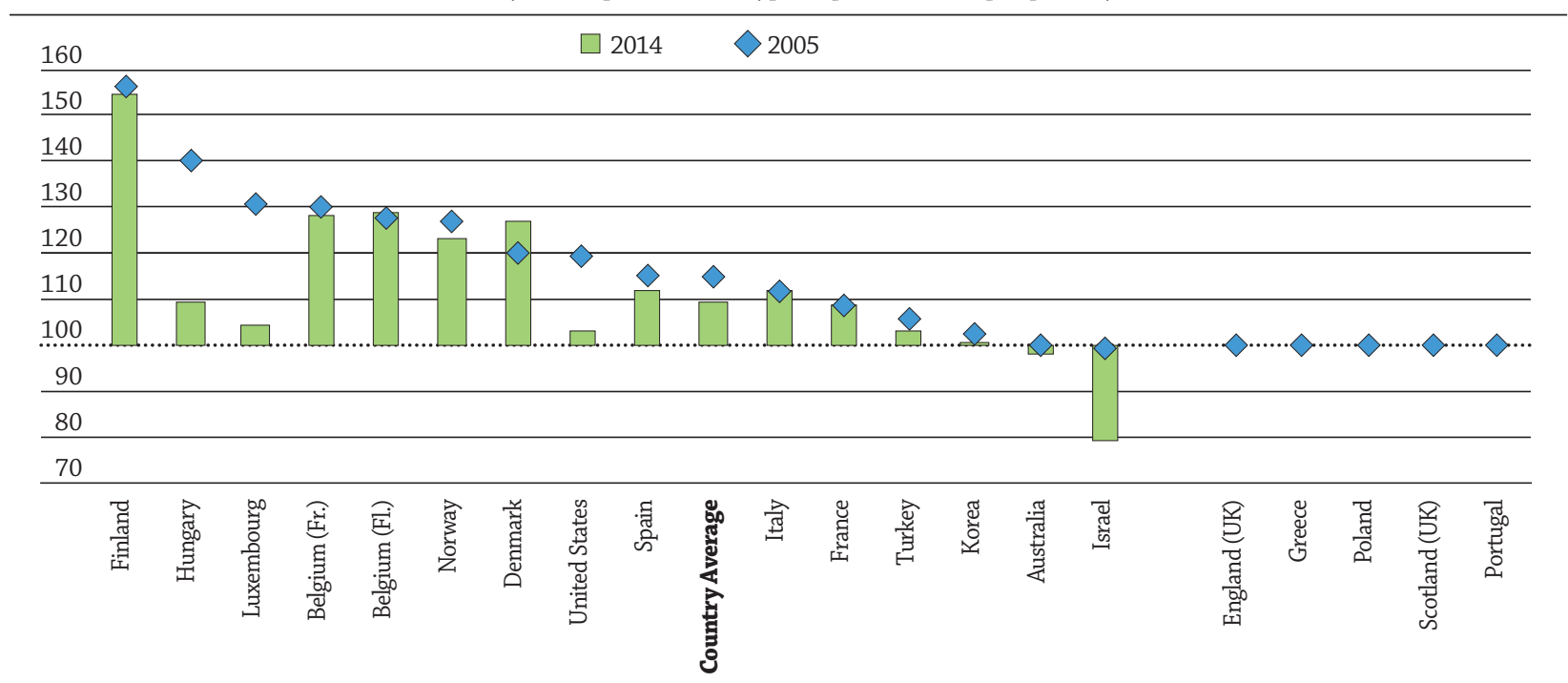

Note: Only countries with data for both years are included.

Countries are ranked in descending order of the ratio in 2005

Source: OECD, Table X2.4c, available on line. See Annex 3 for notes (www.oecd.org/education/education-at-a-glance-19991487.htm).

The statutory salary for a given level of education also varies with teachers' experience, as systems of compensation recognise experience and other factors, such as completion of professional training. For example for lower secondary teachers with typical qualifications, statutory salaries for those with 10 years of experience are $28 \%$ higher than starting salaries on average across OECD countries, and $37 \%$ higher for those with 15 years of experience. An analysis of how salary scales have been stretched or compressed over time might provide some insights into how policy makers have attempted to balance the competing needs of curbing public expenditure while retaining the attractiveness of the teaching profession. However, there is not enough comparable data available over time to allow this kind of analysis.

Teachers' actual salaries remain below those paid in the wider labour market, despite increases in half of countries between 2010 and 2014

Statutory salaries are just one component of teachers' total compensation. In addition to basic pay scales, school systems offer additional payments or other rewards for teachers which may reflect additional tasks and responsibilities (such as management or student counselling), or specific working conditions (for example teaching in particular fields or specific geographical areas). Data on teachers' actual salaries help give a picture of the total remuneration teachers receive.

In 2014, across OECD countries the actual salaries of teachers aged 25-64 averaged USD 38253 at pre-primary level, USD 41300 at primary level, USD 43374 at lower secondary level, and USD 47165 at upper secondary level. Among the few countries with available data for both statutory and actual salaries, actual salaries decreased over the period 2010-14 in about half of the countries, and increased in the other half.

Average actual salaries of teachers are influenced by a range of factors, such as the levels of experience of the teaching force and the prevalence of bonuses and allowances in the compensation system. Consequently, average actual salaries may be higher or lower than statutory salaries. Actual salaries may nevertheless provide a better estimate of teachers' earnings. As such they can be used to assess the attractiveness of the compensation of the teaching profession in different countries compared to other similarly educated professionals (25-64 year-old full-time, full-year workers with a tertiary education). Despite increases in actual salaries in recent years, on average in 2014 across OECD countries, pre-primary teachers' actual salaries are $74 \%$ of the earnings of a tertiaryeducated 25-64 year-old full-time, full-year worker. Primary teachers are paid $81 \%$ of these benchmark earnings, lower secondary teachers $85 \%$ and upper secondary teachers $89 \%$ (Figure 3). 
Figure 3. Teachers' actual salaries relative to wages of tertiary-educated workers, by level of education (2014)

Ratio of salary, using annual average salaries (including bonuses and allowances) of teachers in public institutions relative to the wages of full-time, full-year workers with tertiary education.

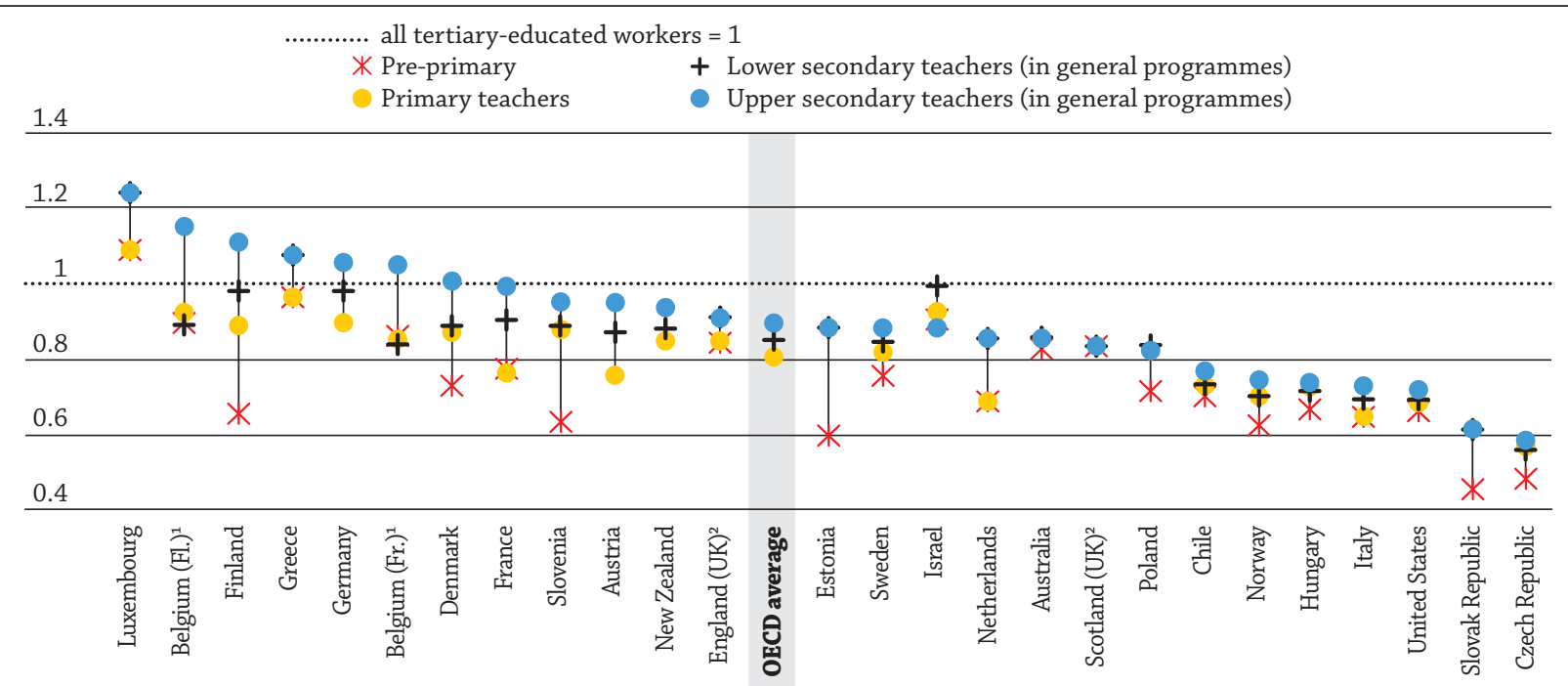

1. Data on earnings for full-time, full-year workers with tertiary education refer to the United Kingdom.

2. Data on earnings for full-time, full-year workers with tertiary education refer to Belgium.

Countries and economies are ranked in descending order of the ratio of upper secondary teachers' salaries to earnings for full-time, full-year tertiary-educated workers. Source: OECD, Table D3.2a. See Annex 3 for notes (www.oecd.org/education/education-at-a-glance-19991487.htm).

In almost all countries with available information, teachers' actual salaries are lower than the earnings of tertiary-educated workers. In only 7 of the 26 countries with available data do upper secondary teachers have actual salaries that are equal to or higher than the earnings of tertiary-educated workers. Comparing the actual salaries of pre-primary, primary and lower secondary teachers to the earnings of tertiary-educated workers shows a similar pattern.

Relative salaries for teachers are highest in Belgium (Flemish Community, upper secondary), Finland (upper secondary) and Luxembourg (lower and upper secondary), where teachers' actual salaries are at least 10\% higher than the earnings of tertiaryeducated workers. The lowest relative teachers' actual salaries are found in the Czech Republic and the Slovak Republic where pre-primary teachers' actual salaries are less than $50 \%$ of the earnings of a full-time, full-year tertiary-educated worker.

The bottom line: The combined effects of policy reforms to attract and/or retain teachers, and financial constraints in the context of the economic downturn in 2008 may explain part of the recent trends in teachers' salaries: decreases in statutory salaries and smaller salary gaps between levels of education. Nevertheless, statutory and/or actual salaries increased significantly in some countries between 2005 and 2014, even if in 2014 teachers' actual salaries remain lower than those of tertiary-educated workers in most countries.

\section{For more information}

OECD (2016), Education at a Glance 2016: OECD Indicators, OECD Publishing, Paris, http://dx.doi.org/10.1787/eag-2016-en.

\section{Contact}

Etienne Albiser (etienne.albiser@oecd.org) and Michael Jacobs (michael.jacobs@oecd.org).

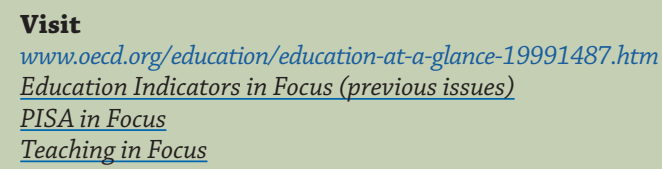

This work is published under the responsibility of the Secretary-General of the OECD. The opinions expressed and arguments employed herein do not necessarily reflect the official views of OECD member countries.

This document and any map included herein are without prejudice to the status of or sovereignty over any territory, to the delimitation of international frontiers and boundaries and to the name of any territory, city or area.

The statistical data for Israel are supplied by and are under the responsibility of the relevant Israeli authorities. The use of such data by the OECD is without prejudice to the status of the Golan Heights, East Jerusalem and Israeli settlements in the West Bank under the terms of international law. 